\title{
RISK OF A MAJOR DEPRESSIVE EPISODE IN ASTHMA AND COPD PATIENTS AMIDST COLOMBIAN SAR-COV-2 CONFINEMENT
}

\author{
Carmen Cecilia Caballero-Domínguez, John Carlos Pedrozo-Pupo \& Adalberto Campo-Arias \\ Facultad de Ciencias de la Salud, Universidad del Magdalena, Santa Marta, Colombia
}

received: 4.12.2020;

revised: 15.1.2021;

accepted: 8.2.2021

\section{SUMMARY}

Background: Chronic non-communicable diseases, such as asthma (AS) and chronic obstructive pulmonary disease (COPD), are a public health problem that compromises patients' quality of life and is highly comorbid with medical and psychological conditions. The present study's objective was to know the variables associated with the risk of major depression during confinement due to SAR-CoV-2 in patients with AS and COPD in the Colombian Caribbean.

Subjects and methods: An online cross-sectional observational study was done with the participation of patients diagnosed with $A S$ or COPD. AS and COPD patients completed the Patient Health Questionnaire (PHQ-9) to identify a major depressive disorder risk.

Results: Two hundred seventy-seven patients diagnosed with AS or COPD aged 18 to $69(M=60.4, S D=17.6)$ participated. The risk of major depression was assessed using the PHQ-9 sent online after telephone contact with the participants. $30.7 \%$ of the patients during the last month reported a risk of major depression, and it was associated with a history of major depressive disorder $(O R=4.39,95 \% C I 1.53-12.67)$ and medical comorbidity $(O R=1.69,95 \% C I 1.00-2.86)$.

Conclusions: The depression risk is associated with a history of depressive disorder and medical comorbidity in patients with AS and COPD. Medical history is the leading risk factor for depression during confinement. It is recommended to carry out studies with many participants and study other variables that may mediate said associations during confinement by SAR-CoV-2 in the Colombian Caribbean.

Key words: chronic obstructive pulmonary disease (COPD) - asthma - depressive disorder - cross-sectional studies

$* * * * *$

\section{INTRODUCTION}

Respiratory diseases such as asthma (AS) and chronic obstructive pulmonary disease (COPD) are non-communicable chronic diseases representing a public health problem. These diseases are responsible for 3.9 million deaths annually, and it is estimated that by 2030 it will be among the four leading causes of death (Kuzmar et al. 2018, World Health Organization 2020). In Colombia, the prevalence of COPD and SA is around $10 \%(\mathrm{Ca}-$ ballero et al. 2008, Kuzmar et al. 2018). Besides, they are considered high-cost diseases for the health system and the patient due to the loss of productivity (Caballero et al. 2008, Pérez-Machón \& Álvarez-García 2017).

More common among COPD than AS patients, dyspnea limits physical activity, emotional and social state (Jonsdottir 1998, Nicoll 2003). Among these factors, a vicious circle is established that limits social and professional functioning and daily situations, with a progressive deterioration in the quality of life, with the need for oxygen and in-hospital services, which leads to patients' social isolation (World Health Organization 2020). This situation affects mood and contributes to developing psychological symptoms and meets the criteria for diagnosing major depressive disorder (Galić et al. 2019, López et al. 2007, Šimić \& Vukojević 2019).

During the current epidemic of Acute Syndrome Coronavirus 2 (SAR-CoV-2) disease, patients with AS or COPD are in a situation of special medical care. This situation can increase morbidity and mortality between
$90 \%$ and $96 \%$ in patients with SAR-CoV-2 (Burke 2020, Lopez et al. 2001, Valdes 2020, Yang et al. 2020, Zhou et al. 2020, Wan et al. 2020). Measures to prevent the spread of SARSAR-CoV-2 and the negative psychosocial consequences of confinement represent a significant stressor for the population (Bornstein 2020).

From the perspective of the diathesis-stress model, the conjugation of the above individual risk factors and stressful or adverse events could be associated with greater vulnerability in patients with COPD and AS during the SAR-CoV-2 epidemic, consequently predisposing or exacerbate symptoms of major depression compared to the general population (Vasquez et al. 2010, Wang 2020). Among mental disorders, major depressive disorder is the most prevalent in patients with AS and COPD (Pérez-Manchón 2017).

At regular times, the prevalence of major depressive disorder can vary between $2 \%$ and $26.5 \%$ depending on the severity of AS and COPD (Coronel-Pazos \& FuentesOrtiz 2018, Marshall 2015, Moussas 2008, Strine 2008). Among the risk factors associated with major depressive disorder in patients with AS or COPD are the proximal social determinants such as age, gender, marital status, and educational level. For example, in a study conducted on 18,856 participants from 38 states of the United States, as well as Puerto Rico, the U.S. Virgin Islands, and the District of Columbia, Tara et al. (2008) found that adults with AS between 18 and 24 years old, women, incomplete secondary education, separated and unemployed have a higher risk of depression. 
In patients with AS and COPD, it can coexist with various medical diseases. Medical comorbidity increases the risk of major depressive disorder. Besides, a history of a depressive episode is related to depression risk among the general population amidst the SARCoV-2 epidemic (Sherman et al. 2020). Similarly, diagnosing lung disease may be associated with major depressive disorder, particularly in patients with COPD (Coronel-Pazos \& Fuentes-Ortiz 2018).

Patients with AS and COPD could present a higher risk of functional deterioration due to diseases' comorbidity and the psychosocial consequences of the SARCoV-2 epidemic (Lopez et al. 2001). The above could exacerbate pre-existing mental health problems (García 2013). However, today, the frequency of depression during the SAR-CoV-19 epidemic confinement in patients with AS and COPD is unknown. This study provides information for the evaluation and clinical treatment of patients with AS and COPD (De Miguel-Díez et al. 2010). The treatment of major depressive disorder favours therapeutic adherence and the prevention of relapses in patients with AS or COPD (García et al. 2013).

The present study's objective was to know the variables associated with the risk of major depression during confinement due to SAR-CoV-2 in patients with $\mathrm{AS}$ and COPD in the Colombian Caribbean.

\section{SUBJECTS AND METHODS}

\section{Research design and ethical considerations}

A cross-sectional observational study was designed. The project was approved by an institutional research ethics committee (Act 002 of March 26th, 2020). The patients participated voluntarily after signing informed consent online. Anonymity and confidential handling of information was guaranteed, consistent with the Helsinki Declaration (World Medical Association 2018).

\section{Sample and selection criteria}

Three hundred seventeen adult patients with asthma or COPD followed in a specialized clinic in Santa Marta, Colombia, were invited to participate. This sample was calculated for an expected prevalence of $25 \%$ risk of a major depressive episode $(+/-5)$, with a $95 \%$ confidence level, to which it added $10 \%$ for eventual losses (Hernández 2006). Besides, this sample size allowed simultaneous adjustment for up to seven variables, at the rate of ten positive cases of risk of a major depressive episode for each variable included in a logistic regression model (Katz 2006).

\section{Variables}

Demographic information was consolidated: age, gender, education, marital status, employment, jobs (health care worker or not), medical comorbidity (diabetes, hypertension or other), history of depressive disorder, and current risk of a major depressive episode.
The risk of a major depressive episode was quantified with the Personal Health Questionnaire (PHQ-9). The PHQ-9 is an instrument that consists of nine items that explore the presence of depressive symptoms during the last month (Kroenke et al. 2001). These symptoms correspond to the criteria included for major depressive disorder in the Diagnostic and Statistical Manual of the American Psychiatric Association fourth revised edition (Kocalevent et al. 2013) and remain unchanged in the fifth version (American Psychiatric Association 2013). This instrument was previously adapted for the Colombian population (Cassiani-Miranda et al. 2017). In Colombian primary care patients, the PHQ-9, for the cut-off point of seven used in the present study, showed a sensitivity of 0.90 , a sensitivity of 0.82 , a positive predictive value of 0.58 , and a negative predictive value of 0.97 (Cassiani-Miranda et al. 2020).

\section{Procedure}

The patients were contacted by telephone. The study's objectives and explained, keeping the answers anonymous and the confidential handling of the information. It was specified that the electronic questionnaire did not allow knowing the IP address or the telephone number used to respond to the research questionnaire. The patients who agreed to participate were sent to the phone to the email that provided the respective link. A second message or email was sent a week later to remind them to complete the questionnaire or to ignore it if they had already filled it out.

\section{Analysis of data}

The traditional descriptive analysis was done for qualitative and quantitative variables. The major depressive episode's risk was the dependent variable and the remaining variables as independent variables. Crude odds ratios with $95 \%$ confidence intervals $(95 \% \mathrm{CI})$ were established, and those variables that showed probability values less than $20 \%$ were considered for a final adjustment. The process was carried out in several steps, and the variables were included in ascending order according to the probability value, as suggested in Greenland's recommendations (1989). The Hosmer-Lemeshow goodness of fit of the final model was calculated to accept the same (Hosmer-Lemeshow et al. 1991). The analysis was completed in the SPSS version 23 program (IBM Corp. 2018).

\section{RESULTS}

Of the 317 phone numbers selected, ten did not exist, 15 did not answer, 292 patients received the questionnaire, 277 patients $(94.9 \%)$ accepted to participate, and 15 patients $(5.1 \%)$ disagreed. The ages were observed between 18 and 96 years $(M=60.4, S D=17.6)$. Eighty-five (30.7\%) participants scored for the risk of a major depressive episode. Table 1 presents more information that is descriptive. 
Table 1. Description of the sample

\begin{tabular}{|c|c|c|}
\hline Variable / Category & $\mathrm{n}$ & $\%$ \\
\hline \multicolumn{3}{|l|}{ Age } \\
\hline Less than 65 years & 150 & 54.2 \\
\hline Older than 65 years & 127 & 45.8 \\
\hline \multicolumn{3}{|l|}{ Gender } \\
\hline Female & 180 & 64.0 \\
\hline Male & 97 & 36.0 \\
\hline \multicolumn{3}{|l|}{ Education } \\
\hline High school or less & 156 & 55.1 \\
\hline College or more & 121 & 44.9 \\
\hline \multicolumn{3}{|l|}{ Stable couple } \\
\hline Yes (Free union or married) & 158 & 57.0 \\
\hline No (Single, separated or widowed) & 119 & 43.0 \\
\hline \multicolumn{3}{|l|}{ Unemployed } \\
\hline Yes & 202 & 72.9 \\
\hline No & 75 & 27.1 \\
\hline \multicolumn{3}{|l|}{ Colombian socioeconomic status } \\
\hline Low (I, II or III) & 193 & 69.7 \\
\hline High (IV, V or VI) & 84 & 30.3 \\
\hline \multicolumn{3}{|l|}{ Health worker } \\
\hline Yes & 19 & 6.9 \\
\hline No & 258 & 93.1 \\
\hline \multicolumn{3}{|l|}{ Medical comorbidity } \\
\hline Yes & 140 & 50.5 \\
\hline No & 137 & 49.5 \\
\hline \multicolumn{3}{|l|}{ Major depressive history } \\
\hline Yes & 16 & 5.8 \\
\hline No & 261 & 94.2 \\
\hline
\end{tabular}

One variable (history of a major depressive disorder) was statistically associated with a major depressive episode's risk. However, medical comorbidity, gender, and health employed were considered for a final adjustment due to these variables showing associations with a p-value of 0.30 . Table 2 shows all crude odds ratios. Finally, depression risk was related to the history of major depressive disorder $(\mathrm{OR}=4.39$, $95 \%$ CI 1.53-12.67), and medical comorbidity ( $\mathrm{OR}=1.69$, $95 \%$ CI 1.00-2.86), Hosmer-Lemeshow test, $\chi^{2}=0.36$, $\mathrm{df}=1, \mathrm{p}=0.55$.

Table 2. Crude associations for depression risk

\begin{tabular}{lcc}
\hline Variable & OR & $95 \%$ CI \\
\hline Age younger than 65 years & 1.23 & $0.73-2.05$ \\
Female gender & 1.44 & $0.83-2.50$ \\
Education high school or less & 1.16 & $0.69-1.94$ \\
Without a stable couple & 1.03 & $0.72-0.73$ \\
Unemployed & 1.09 & $0.61-1.95$ \\
Low socioeconomic status & 1.16 & $0.63-2.03$ \\
Health employed & 1.71 & $0.66-4.42$ \\
Medical comorbidity & 1.66 & $1.00-2.79$ \\
History of major depressive disorder & 4.13 & $1.45-11.78$ \\
Asthma diagnosis & 1.23 & $0.74-2.05$ \\
\hline
\end{tabular}

\section{DISCUSSION}

In the present study, a prevalence of risk of depressive episodes greater than $30.7 \%$ was observed during the last month. It was associated with a history of major depressive disorder and medical comorbidity in patients with AS and COPD during confinement due to SAR-CoV- 2 in the Colombian Caribbean.

The prevalence of the risk of depression in the last month was $30.7 \%$. This prevalence of risk of major depressive episode, quantified with Patient Health Questionnaire-9 (PHQ-9), is very close to that observed in Colombia, before SAR-CoV-2 lockdown, among college students (27.3\%) (Cassiani et al. 2017) and primary care patients (27.2\%) (Cassiani et al. 2020). The prevalence of risk of depression in AS and COPD patients with before the pandemic is unknown. Moreover, there is a lack of Colombian studies in the general population, AS and COPD patients who report the PHQ-9 risk of depression during SAR-CoV-2 lockdown that compare the present study's frequency.

A higher prevalence of risk of depression was expected in this group of patients because, from the perspective of vulnerability, the stress diathesis model predicts that patients who meet a series of risk factors related to the conjugation of various acute stressors, where the number and severity of the stressful event are related to the onset and development of a depressive episode (Hammen 2005). Concern for the medical condition itself and the risk of contagion contributes to the severe and critical evolution of cases, with higher mortality in patients over 60 years of age and with chronic non-communicable diseases, constitutes a significant acute factor for patients with AS and COPD (Valdés 2020, Yang et al. 2020). Other low-intensity stressors accompany the previous, but long-lasting, lifestyle changes derived from compulsory confinement, misinformation, and economic difficulties (CaballeroDomínguez \& Campo Arias 2020, Reinecke 2017, Taylor 2008, Šimić \& Vukojević 2019). Possibly, other factors not analyzed explain a similar prevalence. For example, cultural factors such as familism, very common in the Colombian Caribbean, play a protective role given the attention and care that is usually given to adults with a chronic disease, that is, the epidemic did not imply an additional stressor for these patients (Shum et al. 2014, Thomas et al. 2017).

In the present study, variables such as age, gender, marital status, and educational level are independent of the current major depression in patients with AS and COPD during SAR-CoV-2. These findings differ from what was found in a study conducted at regular times in 18,856 adults with asthma aged 65 or over were less likely to present current depression compared to those aged 18 to 24 years $(\mathrm{OR}=12.4,95 \%$ CI $10.0-15.2)$, incomplete secondary education $(\mathrm{OR}=38.2,95 \% \mathrm{CI} 33.2-$ 43.4), being married ( $\mathrm{OR}=29.5,95 \%$ CI 26.6-32.6), female gender $(\mathrm{OR}=14.9,95 \% \mathrm{CI} 20.1-23.7)$, and being un- 
employed $(\mathrm{OR}=37.8,95 \%$ CI 31.4-44.7) was associated with a major depressive episode (Tara et al. 2008). These differences may be mediated by the variability of populations studied and differences in the countries and the context in which the studies were carried out (Grimes \& Schulz 2002).

The present study showed that a history of depressive disorder in patients with AS and COPD was associated with the risk of a major depressive episode during the last month. These results are consistent with what was observed by Vieira et al. (2017) in regular times; in 18,856 patients with AS in the United States, they found an association between depressive symptoms in the last month with a diagnosis of depression throughout life $(\mathrm{OR}=63.0,95 \%$ CI 59.4-66.4). Besides, Sherman et al. (2020) found in a sample of 599, using online survey during a period during which SAR-CoV-2 infection rates in Arkansas, United States, increased significantly that a positive PHQ-9 screening was associated with a prior history of mental health difficulties $(\mathrm{OR}=4.4,95 \%$ CI 2.6-7.4). Patients with a history of depressive disorder are more susceptible to experiencing more chronic stressors; therefore, greater vulnerability to relapse and experiencing new major depression (Monroe et al. 2007). From this perspective, previous depressive episodes predispose greater accessibility to negative schemas and erroneous, harmful, and dysfunctional information processing (Kendler et al. 2001).

In the current study, medical comorbidity in patients with AS and COPD was associated with last-month major depression. Few studies indicate the relationship between these medical conditions in patients with AS and COPD; However, in Nicaragua, in 200 chronically ill patients, non-communicable comorbidities were associated with depression (Amaya-Silva \& ElvirMendoza 2010). Despite the difference in medical conditions in these studies, some authors point out that comorbidities in patients with AS and COPD are factors that predict more significant stress for the patient and family; therefore, dependence on oxygen and worse hospitalization compromise significant in autonomy and functioning in the different areas, which increases the risk of major depression (De Miguel-Díez et al. 2010, Sayeed et al. 2020, World Health Organization 2020).

This study responds to current mental health needs in periods of confinement. Furthermore, in respiratory diseases such as AS and COPD of chronic course, with remissions and exacerbations, it is necessary to fully understand the risk factors associated with the prognosis during SAR-CoV-2 confinement (Jonsdottir 1998, Nicoll 2003).

SAR-CoV-2 is not a pandemic; it is a syndemic that results from a complex interaction of predisposing individual, social and cultural causes, processes and situations. In chronically ill patients, this set of negative factors becomes more important because they significantly increase susceptibility to psychological suffering, illness, or death (Horton 2020).
Empirical epidemiological references for predictive risk factors favour the design of prevention programs and the clinical management of diseases based on evidence (Carlsson et al. 2017). It is essential to have comprehensive, multi-professional endpoints and treatment in a multimorbidity context associated with AS and COPD (Pandarakalam 2018). Medical treatments combined with psychotherapy and psychoeducation have shown improvement in the control of symptoms and the quality of life of patients (Pérez-Manchón \& ÁlvarezGarcía 2017). Likewise, multidimensional and transdisciplinary techniques for dealing with the crisis derived from the threat caused by SAR-CoV-2 in patients with chronic diseases can have positive effects (Rehman \& Lela 2020).

In the present study, the risk of major depression was estimated using the PHQ-9, which allowed identifying possible cases. A major depressive episode diagnosis requires confirmation by a clinical interview, which was not carried out in the present study. However, in the Colombian population, the PHQ-9 has shown good clinimetric performance, a sensitivity of 0.90 , and a specificity of 0.82 , which guarantees the measurement's validity (Cassiani et al. 2020). These findings must be interpreted with caution because no control group allows validating and contrasting the results during confinement for SAR-CoV-2. Future research is recommended to have larger samples and includes other disorders, such as anxiety, stress, coping, and groups with different severity levels (García et al. 2013). Furthermore, the cross-sectional design does not allow the direction of causality to be identified (Grimes \& Schulz 2002, Sica 2006).

\section{CONCLUSIONS}

It is concluded that depression risk is associated with a depressive disorder history and medical comorbidity among AS and COPD patients during SARS-CoV-2 confinement in the Colombian Caribbean. Future research is recommended to carry out the study with a larger number of participants. It includes variables related to cognitive processes, attitudes related to the control of symptoms, relapses, perception of disease, and its difference with other chronic diseases during and post-pandemic.

\section{Contribution of individual authors:}

Carmen Cecilia Caballero-Domínguez contributed to the study data interpretation, drafted the article, and approved the final version.

John Carlos Pedrozo-Pupo contributed to the study conception and design and data interpretation and revised the intellectual content critically and approved the final version.

Adalberto Campo-Arias contributed to the study conception and design and data interpretation and statistical analysis revised the intellectual content and approved the final version. 


\section{Acknowledgments:}

The data that support the findings of this study are available from the corresponding author upon reasonable request.

\section{Conflict of interest: None to declare.}

\section{References}

1. Amaya-Silva GC \& Elvir-Mendoza YM: [Depression and chronic non-communicable diseases a comparative study of the occurrence and classification of depression among patients treated for chronic non-communicable diseases treated in the primary care consultation in the Municipality of Nindiri, Department of Masaya, and in individuals from the general population in whom it is not diagnosed with chronic disease, November 2009] (Doctoral dissertation, Universidad Nacional Autónoma de Nicaragua, Managua); 2010

2. American Psychiatric Association: Diagnostic and Statistical Manual of Mental Disorders. Fifth Edition. Washington, DC: American Psychiatric Publishing; 2013

3. Bornstein S, Dalan R, Hopkins D, Mingrone G\& Boehm $B$ : Endocrine and metabolic link to coronavirus infection. Nat Rev Endocrinol 2020; 16:1-2

4. Burke RM, Midgley CM, Dratch A, Fenstersheib M, Haupt $T$, Holshue M, et al.: Active monitoring of persons exposed to patients with confirmed COVID-19 - United States. MMWR 2020; 69:245-267

5. Caballero A, Torres-Duque CA, Jaramillo C, Bolivar F, Sanabria F, Osorio P, et al.: Prevalence of COPD in five Colombian cities situated at low, medium, and high altitude (PREPOCOL study). Chest 2008; 133:343-349.

6. Caballero-Domínguez CC \& Campo-Arias A: [Mental health problems in society: An approach from the impact of COVID 19 and quarantine]. Duazary 2020; 17:1-3.

7. Carlsson AC, Wändell P, Ösby U, Zarrinkoub R, Wettermark $B$ \& Ljunggren $G$ : High prevalence of diagnosis of diabetes, depression, anxiety, hypertension, asthma and COPD in the total population of Stockholm, Sweden-a challenge for public health. BMC Public Health 2013; 13:670

8. Cassiani-Miranda CA, Cuadros-Cruz AK, Torres-Pinzón H. Scoppetta O, Pinzón-Tarrazona JH, López-Fuentes WY, et al.: [Validity of the Patient Health Questionnaire-9 (PHQ-9) for depression screening in adult primary care users in Bucaramanga, Colombia]. Rev Colomb Psiquiatr 2020. https://doi.org/10.1016/j.rcp.2019.09.001

9. Cassiani-Miranda CA, Vargas-Hernández MC, PérezAníbal E, Herazo-Bustos MI \& Hernández-Carrillo M: [Reliability and dimensionality of $P H Q-9$ in screening depression symptoms among health science students in Cartagena, 2014]. Biomedica 2017; 37(Suppl. 1):112-120

10. Coronel-Pazos C \& Fuentes-Ortiz K: [Prevalence of exacerbations in patients with chronic obstructive pulmonary disease (COPD) and depression, compared to patients with COPD without depression, who were admitted to the pneumology service of the Carlos Andrade Marin Hospital and Internal Medicine of the San Francisco de Quito Hospital, from June to December of 2018. Multicenter Study]. Degree work prior to obtaining the title of Specialist in Pulmonology. Higher Research and Postgraduate Institute. Quito: UCE. 2019, p. 74

11. De Miguel-Díez J, Carrasco-Garrido P, Rejas-Gutiérrez J, Martin-Centeno A, Gobartt-Vázquez E, HernandezBarrera $V$, et al.: The influence of heart disease on characteristics, quality of life, use of health resources, and costs of COPD in primary care settings. BMC Cardiovasc Disord 2010; 10:8

12. Galić K, Dodaj A, Ćorluka-Čerkez V, Lasic V, Pejić R, Šimiü J et al.: Study of depression and anxiety in patients with asthma and chronic obstructive pulmonary disease. Psychiatr Danub 2019; 31:S112-S117

13. García-Olmos L, Alberquilla Á, Ayala V, García-Sagredo $P$, Morales L, Carmona M, et al.: Comorbidity in patients with chronic obstructive pulmonary disease in family practice: a cross-sectional study. BMC Fam Pract 2013; 14:11

14. Greenland $S:$ Modeling and variable selection in epidemiologic analysis. Am J Public Health 1989; 79:340-349

15. Grimes DA \& Schulz KF: Bias and causal associations in observational research. Lancet 2002; 359:248-252

16. Hammen C: Stress and depression. Ann Rev Clin Psychol 2005; 1:293-319

17. Hernández J: [Size simple for a clinical trial]. Rev Colomb Gastroenterol 2006; 21:118-121

18. Horton R: Offline: COVID-19 is not a pandemic. Lancet 2020; 396:874

19. Hosmer DW, Taber $S \&$ Lemeshow S: The importance of assessing the fit of logistic regression models: a case study. Am J Public Health 1991; 81:1630-1635

20. IBM Corp: IBM SPSS Statistics for Windows, Version 23.0. Armonk, NY: IBM Corp; 2015

21. Jonsdottir H: Life patterns of people with chronic obstructive pulmonary disease: isolation and being closed in. Nurs Sci Q 1998; 11:160-166

22. Katz MN: Multivariable analysis. Second edition. Cambridge: Cambridge University Press; 2006

23. Kendler KS, Thornton LM \& Gardner CO: Genetic risk, number of previous depressive episodes, and stressful life events in predicting the onset of major depression. Am J Psychiatry 2001; 158:582-586

24. Kocalevent RD, Hinz A \& Brähler E: Standardization of the depression screener patient health questionnaire (PHQ-9) in the general population. Gen Hosp Psychiatry 2013; 35:551-555

25. Kroenke K, Spitzer RL \& Williams JB: The PHQ-9: validity of a brief depression severity measure. $J$ Gen Intern Med 2001; 16:606-613

26. Kuzmar I, Giraldo-Ospina C, Acevedo-Osorio G\& Rua S: [Morbidity of chronic obstructive pulmonary disease in Colombia. Results of the Study SANEPOC-2]. Rev Cuba Higiene Epidemiol 2018; 75:19-24

27. Lopez AD, Mathers CD, Ezzati M, Jamison DT \& Murray CJ: Global and regional burden of disease and risk factors, 2001: systematic analysis of population health data. Lancet 2006; 367:1747-1757

28. Marshall G: The impact of anxiety and depression on outpatients with asthma. Ann Allerg Asthma Immunol 2015; 115:333-334

29. Monroe SM, Slavich GM, Torres LD \& Gotlib IH: Major life events and major chronic difficulties are differentially associated with a history of major depressive episodes. $J$ Abnorm Psychol 2007; 116:116-124 
30. Moussas G, Tselebis A, Karkanias A, Stamouli D, Ilias I, Bratis D et al.: A comparative study of anxiety and depression in patients with bronchial asthma, chronic obstructive pulmonary disease, and tuberculosis in a general hospital of chest diseases. Ann Gen Psychiatry 2008; 7:1-4

31. Nicholls DA: The experience of chronic breathlessness. Physiother Theor Pract 2003; 19:123-136.

32. Pandarakalam JP: Challenges of treatment-resistant depression. Psychiatr Danub 2018; 30:273-284.

33. Pérez-Manchón D \& Álvarez-García GM: [Comprehensive assessment of chronic obstructive pulmonary disease in primary care. Quality of life and mortality associated comorbidity]. Aten Primaria 2017; 49:255-256

34. Rehman S, Lela U: Psychological aid to COVID-19 pandemic: A mental health response to crises management. Psychiatr Danub 2020; 32:262-265

35. Reinecke L, Aufenanger S, Beutel ME, Dreier M, Quiring O, Stark B, et al.: Digital stress over the life span: The effects of communication load and internet multitasking on perceived stress and psychological health impairments in a German probability sample. Media Psychol 2017; 20:90-115

36. Sayeed A, Kundu S, Al Banna MH, Christopher E, Hasan MT, Begum MR, et al.: Mental health outcomes of adults with comorbidity and chronic diseases during the COVID19 pandemic: a matched case-control study. Psychiatr Danub 2010; 32:491-498. https://doi.org 10.24869/psyd.2020.491

37. Sherman AC, Williams ML, Amick BC, Hudson TJ \& Messias EL: Mental Health Outcomes Associated with the COVID-19 Pandemic: Prevalence and Risk Factors in a Southern US State. Psychiatry Res 2020; 293:113476

38. Shum J, Poureslami I, Cheng $N \&$ FitzGerald JM: Responsibility for COPD self-management in ethnocultural communities: the role of patient, family member, care provider and the system. Divers Equality Health Care 2014; 11:201-213

39. Sica GT: Bias in research studies. Radiology 2006; 238:780-789

40. Strine TW, Mokdad AH, Balluz LS, Berry JT \& Gonzalez O: Impact of depression and anxiety on quality of life, health behaviors, and asthma control among adults in the United States with asthma, 2006. J Asthma 2008; 45:123-133

41. Šimić J \& Vukojević M: Study of depression and anxiety in patients with asthma and chronic obstructive pulmonary disease. Psychiatr Danub 2019; 31(suppl. 1):S112-S117

42. Tara S, Mokdad L, Balluz L, Berry $T$ \& Gonzalez O: Impact of depression and anxiety on quality of life, health behaviors, and asthma control among adults in the United States with asthma, 2006. J Asthma 2008; 45:123-133

43. Taylor MR, Agho KE, Stevens GJ \& Raphael B: Factors influencing psychological distress during a disease epidemic: data from Australia's first outbreak of equine influenza. BMC Public Health 2008; 8:347

44. Thomas $P A$, Liu $H \&$ Umberson D: Family relationships and well-being. Innov Aging 2017; 1:igx025

45. Valdés M: [Non-communicable chronic diseases and the COVID-19 pandemic]. Rev Finlay 2020; 10:77-87

46. Vasquez C, Hervás $G$, Hernangoméz L \& Romero $N$ : Cognitive models of depression: a synthesis and new proposal based on 30 years of research. Psicol Conduct 2010; 18:139-165

47. Vieira AA, Santoro IL, Dracoulakis S, Caetano LB \& Fernandes AL: Anxiety and depression in asthma patients: impact on asthma control. J Bras Pneumol 2011; 37:13-18

48. Wang D, Hu B, Hu C, Zhu F, Liu X, Zhang J, et al.: Clinical characteristics of 138 hospitalized patients with 2019 novel coronavirus-infected pneumonia in Wuhan, China. JAMA 2020; 323:1061-1069.

49. World Health Organization: Chronic respiratory diseases. Geneva; 2000

50. World Medical Association: Declaration of Helsinki. Seoul, Korea: WMA; 2018

51. Yang J, Zheng Y, Gou X, Pu K, Chen Z, Guo Q, et al.: Prevalence of comorbidities in the novel Wuhan coronavirus (COVID-19) infection: a systematic review and meta-analysis. Int J Infect Dis 2020; 94:91-95

52. Zhou F, Yu T, Du R, Fan G \& Lui Y: Clinical course and risk factors for mortality of adult inpatients with COVID19 in Wuhan, China: A retrospective cohort study. Lancet 2020; 395:1-20
Correspondence:

Ass. Prof. Adalberto Campo-Arias, MD

Facultad de Ciencias de la Salud, Universidad del Magdalena

Carrera 32 No. 22-08, Santa Marta, 470004, Colombia

E-mail:acampo@unimagdalena.edu.co 